\title{
CORRELATIONS BETWEEN NOISE LEVEL AND MECHANICAL VIBRATIONS EMITTED BY VIBORACOUSTIC SOURCES
}

\author{
Mihai Bratu ${ }^{1}$, Ovidiu Vasile ${ }^{2}$,Elena Bucur ${ }^{1}$, Valeriu Danciulescu${ }^{1}$, Mihaela Petrescu ${ }^{1}$ \\ ${ }^{1}$ National Research and Development Institute for Industrial Ecology - ECOIND, 71-73 \\ Drumul Podu Dambovitei Street, sector 6, zip 060652, Bucharest, Romania \\ 2 Dept. Mechanical., Polytechnic University of Bucharest, no. 313, Splaiul Independenței, sector \\ 6, Bucharest, Romania 060042
}

\begin{abstract}
Economic development brings environmental concerns in general and in particular regarding the protection against the aggression of external factors on humans, among which noise and vibration. Noise is usually defined as a sound or the amount of unwanted sounds, a by-product of daily activity. Environment vibrations that human body is exposed to may have different causes: construction machinery, heavy equipment and electric hand tools. Whole human body vibrations usually occur during transport, but can be found in other places in the course of industrial processes. Regardless of industrial activity that cause them, vibrations acts on the human body and this can cause discomfort to the operator. Wear of the components of industrial devices influences both noise and mechanical vibration levels. The paper presents correlations occurring between noise and mechanical vibrations emitted by the engine of a car depending on the number of engine revs. For a broader characterization of emission, acoustic power and directivity factor are calculated.
\end{abstract}

Keywords: noise, mechanical vibration, acoustic power, directivity factor

\section{Introduction}

We live in a world of sounds without doubt essential in terms of communication and/or transfer of information. The population today lives in a world with an acoustic environment radically different from any other known in history. Due to its harmful and its presence in all departments of life, noise pollution is a major problem in all countries where we are witnessing a phenomenon of increased noise levels. Noise is a risk factor that has harmful effects on the human body, which can lead to disturbances of the organ of hearing; disorders of various organs and body apparatuses; reducing labour productivity; reduce the intelligibility of speech [1-4].

Vibratory movement is defined as a movement of a mechanical system, limited in space, where the geometric and kinematic parameters that determine the positions of the items changes its alternative meaning of variation in time between well defined values [5 ] .

On machines, vehicles and buildings, their effect is to wear, poor performance, poor functioning or causing any degree of irreversible failure. Many of the problems of noise and vibration are related to the phenomenon of resonance. For every situation there are always three factors:

$>\quad$ Source - where power is generated dynamically

$>\quad$ Path - explains how energy is transmitted

$>\quad$ The receiver - how much noise or vibration can be tolerated.

Any of these can be a cause and should be studied to find the best appropriate solutions. If we consider a vehicle whose noise level is extremely high, the sources of vibration are the engine 
and the gearbox, transmission path is the car body and the receiver is represented by tabs driver [6]. The paper presents the results of tests made to determine the sound pressure level and its correlation with the level of mechanical vibrations emitted by the engine of a car. During test has been determined the acoustic power and directivity as full characteristics of sound power .

\section{Experimental}

In order to determine the mechanical noise and vibration measurements were carried out respecting the requirements of the standards in force [7-9]. Source NVH has been the engine of a car with the following characteristics: engine capacity 1.2 liter $47 \mathrm{~kW}$ (64 hp) gasoline engine with three cylinders. Noise determinations were carried out at different engine speeds: 700 rev / $\mathrm{min} ; 2000 \mathrm{rev} / \mathrm{min}$ and $3000 \mathrm{r} / \mathrm{min}, 2 \mathrm{~m}$ car in 8 points located around the car, one at $45^{\circ}$ to each other (Figure 1).
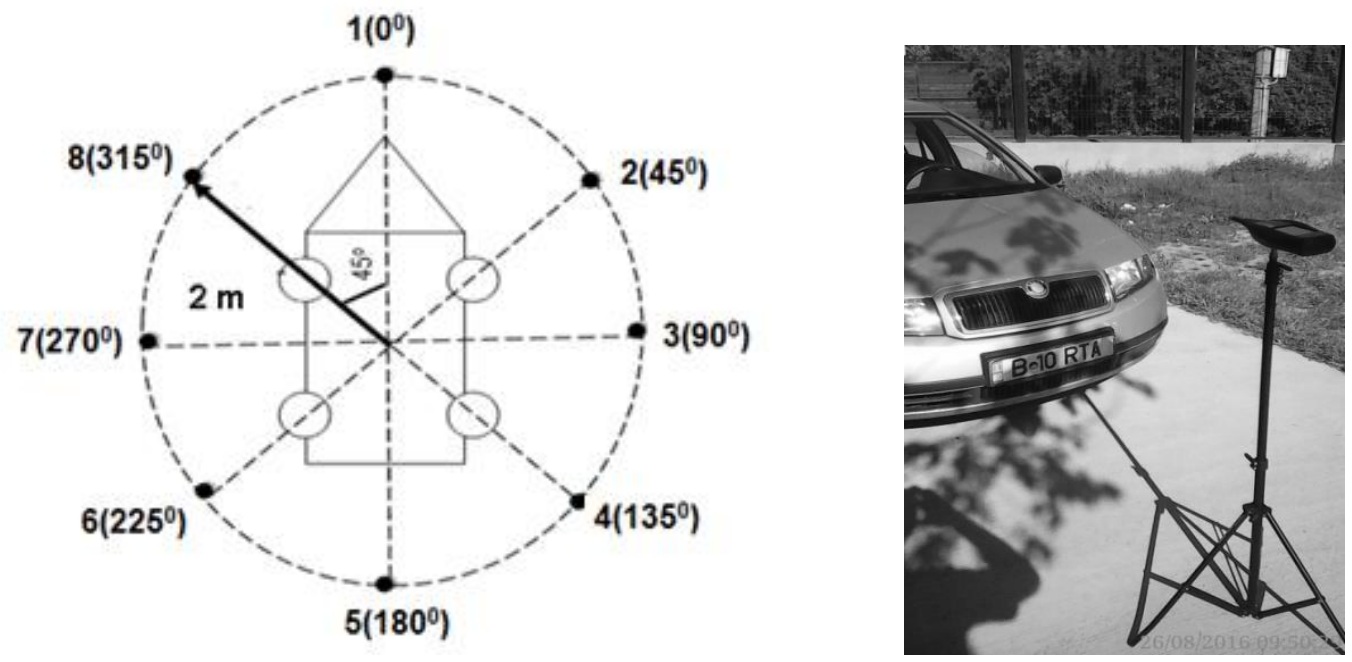

Figure 1. Noise level measureme; monitoring points

To determine the level of vibration measurements were carried out simultaneously with the noise level and under the same conditions, the three engine speeds as shown in Figure 2, vibrometer being mounted on the floor of the car.

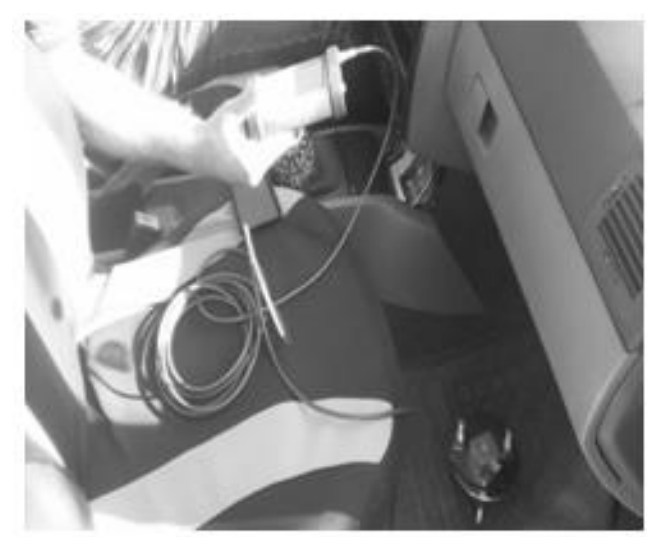

Figure 2. Measurement of mechanical vibration on the three engine revolutions 
Noise measurements were made using sound-level meter for measuring SOLO 01 Metravib and mechanical vibration vibrometer was used SVANTEK 958 (Figure 3).

(a)
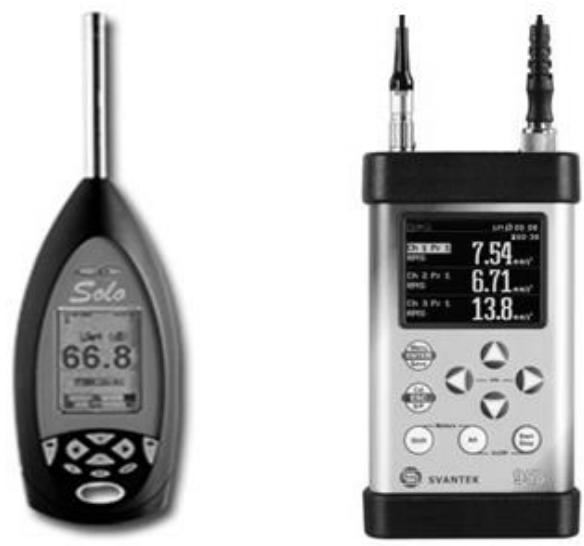

(b)

Figure 3. Sonometer SOLO Metravib 01 (a); Vibrometer SVANTEK 958 (b)

The results were used for: i) calculation of sound power and directivity curve and ii) carrying out correlations of these parameters depending on the level of functioning of the source analysed car engine.

Sound power of a source is the total acoustic emission source in watts. Lw sound power level is expressed in decibels $(\mathrm{dB})$ and is calculated using the following relationship $[10,12]$ :

$\mathrm{Lw}=10 \log \left(\frac{P}{P_{0}}\right)$ , [dB]

where: $\mathrm{P}$ - source acoustic power in $[\mathrm{W}]$;

$\mathrm{P}_{0}-$ reference acoustic power, $\mathrm{P}_{0}=10^{-12}[\mathrm{~W}]$.

Noise source studied - the car engine - is a monopoly source and can be assimilated to a point source. Thus, the source was studied in free field and sound power level, , $L_{w a}$ is calculated using the average sound pressure $L_{p m}$ knowing measuring surface $S$ :

$\mathrm{L}_{w a}=\mathrm{L}_{\mathrm{pm}}+10 \log \left(\frac{s}{s_{0}}\right)+\mathrm{K} \quad,[\mathrm{dB}]$

$\mathrm{L}_{\mathrm{pm}}=\sum_{1}^{8} L_{p i} / 8$

where : $S_{0}=1 \mathrm{~m}^{2}$ the area of the reference surface;

$\mathrm{S}=\pi \mathrm{r}^{2} \mathrm{~m}^{2}$, will be calculated for $\mathrm{r}=2 \mathrm{~m} \rightarrow \mathrm{S}_{0}=12.56 \mathrm{~m}^{2}$

$\mathrm{K}=$ correction coefficient based on normal temperature and pressure conditions $\left(20^{\circ} \mathrm{C}\right.$ si 1013 $\mathrm{hPa}$ ); for these conditions $\mathrm{K}=0$; replacing these values in equation (3) we get:

$\mathrm{L}_{w a}=\mathrm{Lpm}_{\mathrm{pm}}+10 \log 12.56 \quad,[\mathrm{~dB}]$

The sound pressure level is calculated [13] using the relationship (5):

$L_{p m a}=10 \log \left[\frac{1}{n} \sum_{1}^{n} 10^{0,1 L_{p i A}}\right] \quad,[\mathrm{dB}]$

Noise source or the engine of the car is in open field and thus the relationship of connection between sound pressure level and sound power level is [14] on the relation (6):

$L_{p}=L_{w}-20 \log r-11$

, $[\mathrm{dB}]$

where : $L_{p}$ - the level of the sound pressure of the source [dB]

$\mathrm{L}_{w}$ - the level of the sound power of the source [dB] 


$$
r \text {-distance from receptor }
$$

[m]

Directivity factor is owned by a transmitter to radiate sound waves - sound field - in certain directions [11] and is calculated using the equation:

$D_{\theta i}=L_{p i}-L_{w}+20 \log r+11$

\section{Results and Discussion}

Values of noise measurements carried out in 8 points around the car for the three situations Lpm average sound pressure level measured, sound power level LwA calculated and mechanical vibration levels are presented in Table 1.

Table 1. Experimental results of sound pressure level

$\begin{array}{cccccccccccc}\begin{array}{c}\text { Speed } \\ \text { engine }\end{array} & \mathrm{L}_{\mathrm{p} 1} & \mathrm{~L}_{\mathrm{p} 2} & \mathrm{~L}_{\mathrm{p} 3} & \mathrm{~L}_{\mathrm{p} 4} & \mathrm{~L}_{\mathrm{p} 5} & \mathrm{~L}_{\mathrm{p} 6} & \mathrm{~L}_{\mathrm{p} 7} & \mathrm{~L}_{\mathrm{p} 8} & \mathrm{~L}_{\mathrm{pm}} & \mathrm{L}_{\mathrm{wa}} & \text { mechanical } \\ 700 & 54.6 & 55.8 & 50.3 & 49.6 & 46.5 & 47.9 & 49.6 & 55.4 & 51.2 & 62.2 & 1.05 \mathrm{~mm} / \mathrm{s}^{2} \\ 2000 & 65.2 & 65.6 & 61.6 & 63.2 & 61.3 & 6.4 & 63.7 & 64.7 & 63.5 & 74.5 & 624 \mu \mathrm{m} / \mathrm{s}^{2} \\ 3000 & 70.3 & 71.6 & 67.8 & 66.5 & 66.2 & 65.9 & 68.5 & 69.9 & 68.3 & 79.3 & 282 \mu \mathrm{m} / \mathrm{s}^{2}\end{array}$

Can be observed high sound pressure values measured in points 1,2 and 8 points located in front of the car, as shown in Figure 1. Also, there was an increase in noise levels directly proportional to the number of revs motor. In terms of the level of mechanical vibrations, these correlate with default noise and the number of revolutions / minute.

Thus, there is a noticeable decrease in the level of mechanical vibrations, to increase the number of revolutions / minute. For each case 700, 2000 and $3000 \mathrm{rev} / \mathrm{min}$ was calculated factor directivity $D_{\theta i}$ with equation (7) using the values of sound pressure level, $L_{p i}$, at every point and acoustic power, LwA, calculated using the equation (2). The resulting values are presented in Table 3 for the three speeds: 700, 2000 and $3000 \mathrm{rev} / \mathrm{min}$.

Table 3. Calculation of directivity for sample to $700,2000,3000 \mathrm{rot} / \mathrm{min}$ of the motor car

\begin{tabular}{|c|c|c|c|c|c|c|c|c|}
\hline Measuring point & $\mathrm{P} 1$ & $\mathrm{P} 2$ & P3 & $\mathrm{P} 4$ & P5 & $\mathrm{P} 6$ & P7 & P8 \\
\hline \multicolumn{9}{|c|}{$700 \mathrm{rot} / \mathrm{min}$} \\
\hline$\theta \mathrm{i}$ & $0^{\circ}$ & $45^{\circ}$ & $90^{\circ}$ & $135^{\circ}$ & $180^{\circ}$ & $225^{\circ}$ & $270^{\circ}$ & $315^{\circ}$ \\
\hline $\mathrm{L}_{\mathrm{pi}}$ & 54.6 & 55.8 & 50.3 & 49.6 & 46.5 & 47.9 & 49.6 & 55.4 \\
\hline $\mathrm{D}_{\theta \mathrm{i}}$ & 9.4 & 10.6 & 5.1 & 4.4 & 1.3 & 2.7 & 4.4 & 10.2 \\
\hline \multicolumn{9}{|c|}{$2000 \mathrm{rot} / \mathrm{min}$} \\
\hline$\theta \mathrm{i}$ & $0^{\circ}$ & $45^{\circ}$ & $90^{\circ}$ & $135^{\circ}$ & $180^{\circ}$ & $225^{\circ}$ & $270^{\circ}$ & $315^{\circ}$ \\
\hline $\mathrm{L}_{\mathrm{pi}}$ & 65.2 & 65.6 & 61.6 & 63.2 & 61.3 & 6.4 & 63.7 & 64.7 \\
\hline $\mathrm{D}_{\theta \mathrm{i}}$ & 7.8 & 8.2 & 4.2 & 5.8 & 3.9 & 5.0 & 6.3 & 7.3 \\
\hline \multicolumn{9}{|c|}{$3000 \mathrm{rot} / \mathrm{min}$} \\
\hline$\theta \mathrm{i}$ & $0^{\circ}$ & $45^{\circ}$ & $90^{\circ}$ & $135^{\circ}$ & $180^{\circ}$ & $225^{\circ}$ & $270^{\circ}$ & $315^{\circ}$ \\
\hline $\mathrm{L}_{\mathrm{pi}}$ & 70.3 & 71.6 & 67.8 & 66.5 & 66.2 & 65.9 & 68.5 & 69.9 \\
\hline $\mathrm{D}_{\theta \mathrm{i}}$ & 8.0 & 9.3 & 5.5 & 4.2 & 3.9 & 3.6 & 6.2 & 7.6 \\
\hline
\end{tabular}


For each case was done, a dispersion diagram of the noise factor is plotted with directivity and sound pressure level of $700 \mathrm{rev} / \mathrm{min}$ - (a); $2000 \mathrm{rev} / \mathrm{min}$ - (b); $3000 \mathrm{rev} / \mathrm{min}$ - (c)

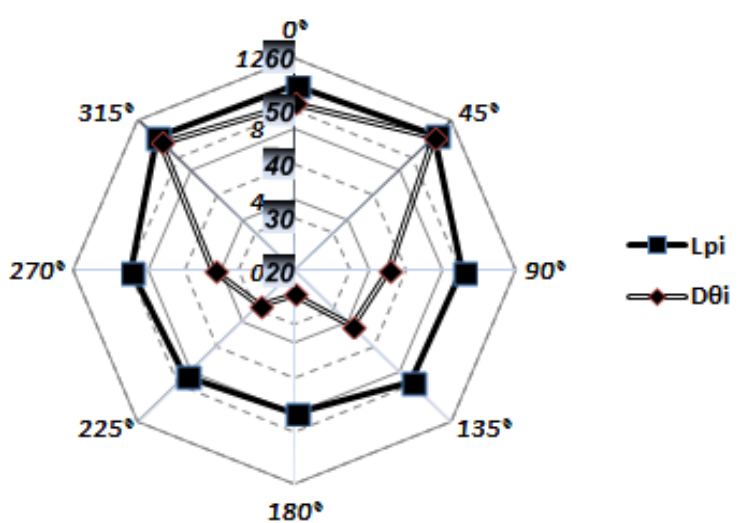

(a)

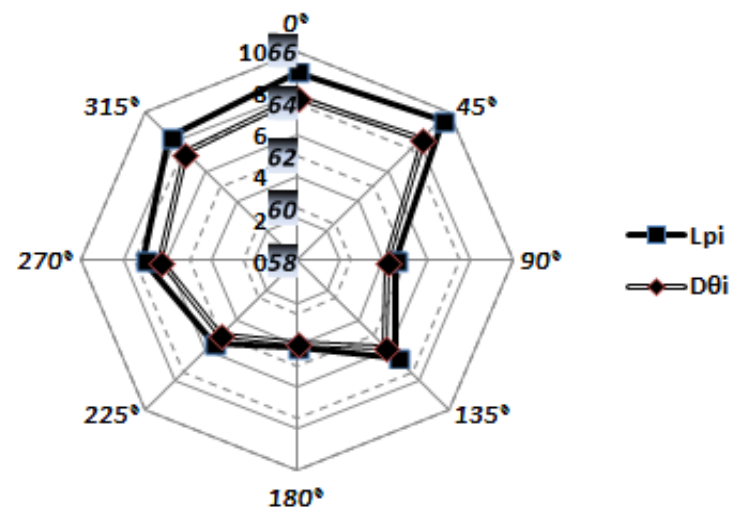

(b)

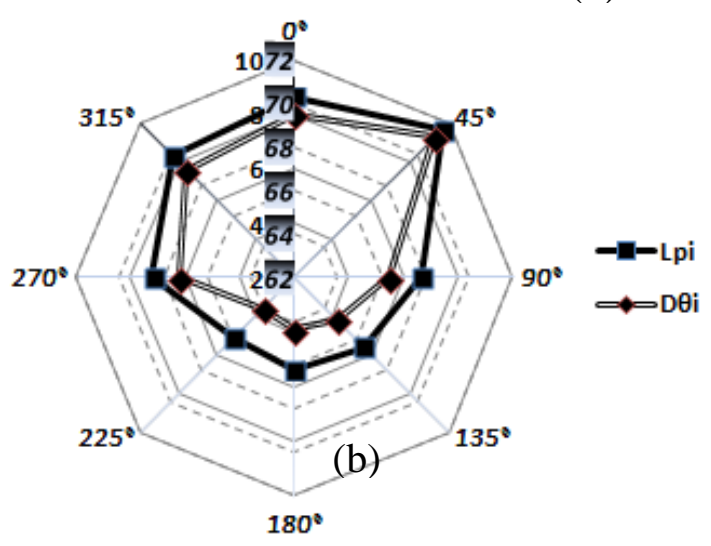

(c)

In the first case, $700 \mathrm{rev} / \mathrm{min}$, we see a small value for the directivity factor and sound power for points 5 and 6 points respectively at 1800 and 2250 points on the circle of rotation around the car. The small amounts of these points is explained by the fact that they are placed behind the car as you can see in the diagram in Figure 1. The level of mechanical vibrations determined at $700 \mathrm{rev} / \mathrm{min}$, at floor on the of passenger side driver is $1.05 \mathrm{~mm} / \mathrm{s}^{2}$, value within normal limits according to GD 1876/2005 [15].

For the second case at $2000 \mathrm{rev} / \mathrm{min}$ the lowest values for the directivity factor, calculated and graphic represented are in section 5 and section 3. Mechanical vibrations are $624 \mu \mathrm{m} / \mathrm{s}^{2}$.

For the third case for $3000 \mathrm{rev} / \mathrm{min}$ noise level increases considerably. According to the graph from Figure 6 can be observed a high value for the directivity factor at point 2. Furthermore, according to Table 2 the mechanical vibration levels measured at $3000 \mathrm{rev} / \mathrm{min}$ is $282 \mu \mathrm{m} / \mathrm{s}^{2}$, the value is lower than the one measured at $2000 \mathrm{rev} / \mathrm{min}$ and $700 \mathrm{rev} / \mathrm{min}$.

Thus we see that the noise level increases with increasing engine revolutions and values obtained depend on the location of the measuring point. Also, the mechanical vibration decreases with increasing number of revolutions/minute source studied. 


\section{Conclusions}

Noise and vibrations caused by car engines are important factors with direct impact on the health of people in transit. In the framework of the study were conducted measurements of noise and mechanical vibrations emitted by the engine of a car at three different engine revolutions: 700 $\mathrm{rev} / \mathrm{min}, 2000 \mathrm{rot} / \mathrm{min}$ and $3000 \mathrm{rot} / \mathrm{min}$. Noise measurements were done in 8 points placed around the car $45^{0}$ to each other and for vibrations in one point, the floor of the car. The results of measurements showed lower values of noise in the points behind the car compared to the front of the car, a situation supported by directivity factor values.

It can also be observed a direct correlation between noise and engine revolutions and an inverse correlation between engine revolutions and vibration levels. Thus, the higher the revolutions, the noise level increases and the vibration levels are reduced.

Next we propose to further the studies on the correlation of mechanical noise and vibration in other situations and for other emission sources.

\section{Acknowledgments:}

The authors are grateful for the financial support of project PN 162502 12-2016 (Contract no.38N/2016)

\section{References}

[1] Muzet A., (2007), Environmental noise, sleep and health, Sleep Medicine Reviews, vol.11, no 2, pag. 135-142, .

[2] Drug G., (2011), Noise pollution in lasi factors discomfort and health risks exposed, (PhD Thesis), University of Medicine and Pharmacy "GR. T. POPA "IAŞI .

[3] Beranek L., (1970), The noise problem in the textile industry, Textile Industries, vol 134, no. 6, pag 113-117.

[4] Darabont, A.(1971), Modern means of combating noise and vibration, Central Institute of Technical Documentation, Bucharest.

[5] Ursu, N., F., (1984), Mechanical vibration, Cluj Napoca Polytechnic Institute, Faculty of Mechanics, Cluj-Napoca, 252 pag..

[6] Bratu P, (1982), Isolation and vibration damping construction engines, Publisher Institute of Construction and Economy Construction Research , Bucharest.

[7] SR 6161-1, (2008), Noise measurement in civil engineering. Measuring methods.

[8] SR ISO 2631-1, (2001) Mechanical vibration and shock. Evaluation of human exposure to whole-body vibration. Part 1: General Requirements.

[9] SR ISO 1996-1, (2008) - Description and measurement of environmental noise. Basic quantities and procedures.

[10] Bratu, P, (2002), Construction and car interior acoustics, Ed. Impuls, Bucharest.

[11] Enescu, N., Magheti, I., Sarbu, M.A., 1998,Acoustic technique, Ed. ICPE, Buchrest.

[12] Vasile, O., (2013) Acoustic technique - Laboratory Guidebook, Ed. Politehnica Press, Bucharest.

[13] Iașnicu I., Vasile, O., (2015), IATAN R., Thickness influence on absorbing properties of stratified composite materials, Journal of Engineering Studies and Research, Volume 21, No. 4, 28-34.

[14] Anghel L, (2008), Sound pressure level calculation relations depending on the sound power level and the type of sound source and field, Comfort, Efficiency, Energy Conservation and Environmental Protection, ISSN 1842 - 6131, Bucharest, 26-27 November.

[15] Government decision 1876/2005. Minimum health and safety requirements regarding the exposure of workers to the risks arising from vibrations. 